\title{
ÁNALISE COMPARATIVA DA AVALIAÇÃO NO ENSINO SUPERIOR: UMA VISÃO DO PROCESSO DE BOLONHA E DO SISTEMA DE AVALIAÇÃO AMERICANO
}

\author{
N. V. C. Vasconcelos' ${ }^{1}$ F. C. B. P. Queiroz, J. V. Queiroz, P. C. Fernandes e D. V. P. Andrade \\ Universidade Federal do Rio Grande do Norte \\ nataliaveloso@hotmail.com ${ }^{1}$
}

Artigo submetido em outubro/2011 e aceito em junho/2012

\section{RESUMO}

Este estudo tem a finalidade de comparar, em traços gerais, a Educação Superior Americana e Européia, a partir do Sistema de Avaliação Americana e o Processo de Bolonha. Identificando e compreendendo as recentes transformações no ensino superior. São analisadas as principais características de ambos os sistemas, examinando a interligação progressiva dos espaços da política de educação superior. Como resultado, observamos que a Declaração de Bolonha, apela à urgência das exigências da competitividade internacional do ensino superior. Tem sido considerada com "a chave" para promover a mobilidade, superando o ensino superior dos Estados Unidos, e consequentemente ocorrendo perdas de interesses dos estudantes

PALAVRAS-CHAVE: sistema de avaliação, ensino superior, educação.

\section{COMPARATIVE ANALYSIS OF ASSESSMENT IN HIGHER EDUCATION: A VISION OF THE BOLOGNA PROCESS AND THE AMERICAN SYSTEM EVALUATION}

\section{ABSTRACT}

This study aims to compare, in broad terms, the American and European Higher Education from the American Evaluation System and the Bologna Process. Identifying and understanding the recent changes in higher education. It analyzes the main characteristics of both systems by examining the continued interconnection of the spaces of higher education policy.
Our results indicate that the Bologna Declaration calls for urgent requirements of the international competitiveness of higher education. It has been considered a "key" to promote mobility, exceeding the U.S. higher education, and the resultant loss of interest of foreign students.

KEY-WORDS: evaluation system, higher education, education. 


\section{ÁNALISE COMPARATIVA DA AVALIAÇÃO NO ENSINO SUPERIOR: UMA VISÃO DO PROCESSO DE BOLONHA E DO SISTEMA DE AVALIAÇÃO AMERICANO}

\section{INTRODUÇÃO}

Conforme Robertson (2009) em muitas partes do mundo a educação superior é vista como um motor para o desenvolvimento de uma economia baseada no conhecimento; as políticas, os programas e as práticas da educação superior são cada vez mais cooptados e dimensionados por interesses políticos e econômicos geoestratégicos mais amplos. E foi isso que percebemos quando aprofundamos os estudos sobre o Processo de Bolonha e o Sistema de Avaliação Americana.

$\mathrm{Na}$ sociedade contemporânea, novos conceitos, valores, saberes e relações se estabelecem e começam a emergir a partir da presença do fenômeno da "quebra de fronteiras", que tem em sua essência, uma nova razão que, em principio, é incompatível com o atual sistema educacional que permanece fechado, linear, e também bastante questionado, em praticamente todos os países do mundo.

Assim, a circulação das ideias e da cultura universitária, a internacionalização, regulação e a competitividade, coadunam com as ideias de integração econômica e unificação política que se inicia a partir da segunda metade Século XX.

Em 1998, em Paris, os ministros da educação da Alemanha, França, Itália e reino Unido assinaram uma declaração (Declaração da Sorbone, 1998). No ano seguinte, os ministros de vinte e nove Estados europeus, subscreveram a Declaração de Bolonha, em que assumem como objetivos promover um espaço europeu de educação superior coerente, compatível, atrativo e principalmente competitivo, fazendo com que os Estados Unidos perdessem significativamente o número de alunos estrangeiros.

O sistema de avaliação do ensino superior americano é feito por meio da acreditação das universidades e faculdades através de associações de acreditação. Existem duas organizações que reconhecem essas agências de acreditação nos Estados Unidos, o departamento de educação nos Estados Unidos, U.S Department of Education (USDE), ou Council for Higher Education Acreditation (CHEA), conselho de reconhecimento do ensino superior. Muitos estados americanos exigem o registro de suas faculdades e universidades presenciais em associações regionais de acreditação.

O reconhecimento das instituições de ensino superior nos Estados Unidos é opcional por parte das instituições. È um processo não governamental, um processo independente. Existem dois tipos de reconhecimento: Reconhecimento Institucional e por organizações profissionais.

Diante do explanado o objetivo deste artigo é descrever como acontece o processo de avaliação do ensino superior americano e o processo de avaliação europeu, denominado como processo de Bolonha, ao final da descrição fazer um comparativo entre as duas metodologias.

Assim, este artigo está dividido em 6 seções. Esta primeira introdutória, onde se apresenta o assunto e o objetivo do estudo. A seção 2 expõe os conceitos referente ao processo de Bolonha, e nas subseções deste tópico apresentam-se aspectos como metas do processo de Bolonha, alguns documentos sobre o processo e informações sobre o processo de transição. A 
seção 3 é destinada ao ensino superior americano, explanando como ocorre o processo de avaliação do ensino superior. Na seção 4 é feito um comparativo entre a metodologia Europeia $x$ metodologia Americana e na seção 5 são feitas as considerações finais, em seguida as referências utilizadas na pesquisa.

\section{PROCESSO DE BOLONHA - NOVO ESPAÇO EUROPEU DE EDUCAÇÃO SUPERIOR}

Em 1998, em Paris, os ministros da educação da Alemanha, França, Itália e Reino Unido assinaram uma declaração conjunta onde a intenção é de promover a construção de um "espaço europeu de educação superior" para responder as exigências de uma nova sociedade (Declaração da Sorbonne, 1998). No ano seguinte, os ministros de 29 países europeus (Para além dos 29 signatários iniciais, aderiram à Declaração de Bolonha até a reunião de ministros de Lovaina (2009) mais 18 países) subscreveram a Declaração de Bolonha, em 19 de Junho de 1999 - que desencadeou o denominado Processo de Bolonha - reunidos na cidade italiana de Bolonha.

A declaração marca uma mudança em relação às políticas ligadas ao ensino superior dos países envolvidos e procura estabelecer uma Área Europeia de Ensino Superior a partir do comprometimento dos países europeus em promover reformas de seus sistemas de ensino, para se adaptarem às necessidades de mudança, às exigências da sociedade e aos avanços do conhecimento científico, ou seja, é a necessidade de retomar o papel da Europa na Educação Superior no contexto global - a Europa do Conhecimento.

Embora a Declaração de Bolonha não seja um tratado, os governos dos países signatários comprometem-se a reorganizar os sistemas de ensino superior dos seus países de acordo com os princípios dela constantes.

A declaração visa a tomada de ações conjuntas para com o ensino superior dos países pertencentes à União Europeia, com o objetivo principal de elevar a competitividade internacional do sistema europeu do ensino superior. Para assegurar que o sistema europeu do ensino superior consiga adquirir um grau de atração mundial semelhante ao das suas extraordinárias tradições cultural e científica, delinearam-se os seguintes objetivos:

Promover entre os cidadãos europeus a empregabilidade e a competitividade internacional do sistema europeu do Ensino Superior. Adotar um sistema baseado em três ciclos de estudos:

$$
\begin{aligned}
& \checkmark \quad \text { 1.o ciclo, com duração mínima de três anos - grau de } \\
& \text { licença; } \\
& \checkmark \quad \text { 2.o ciclo, com a duração de um ano e meio a dois } \\
& \text { (excepcionalmente um ano) - grau de mestre; } \\
& \checkmark \quad \text { 3.o ciclo-grau de doutor. }
\end{aligned}
$$

Implementar o suplemento ao diploma. São automaticamente reconhecidos em todos os estados aderentes, facilitando dessa forma, o reconhecimento das qualificações e a mobilidade das pessoas.

Estabelecer um sistema de créditos transferíveis e acumuláveis (ECTS), comum aos países europeus, para promover a mobilidade mais alargada dos estudantes. (Os créditos podem também ser adquiridos em contextos de ensino não superior, incluindo a aprendizagem ao longo 
da vida, desde que sejam reconhecidos pelos estabelecimentos de ensino superior de acolhimento)

Promover a cooperação europeia na avaliação da qualidade, com vista a desenvolver critérios e metodologias comparáveis. Promover as dimensões europeias do ensino superior, em partículas:

$\checkmark$ Desenvolvimento curricular;

$\checkmark$ Cooperação interinstitucional;

$\checkmark$ Mobilidade de estudantes, docentes e investigadores;

$\checkmark$ Programas integrados de estudo, de formação e de investigação.

O Processo de Bolonha significa reorganizar o processo formativo em torno de novos valores: as competências e não só os conteúdos, as aprendizagens e não simplesmente o ensino, a participação e o envolvimento de todos os agentes implicados e não apenas a participação de professores nas aulas e de estudantes no estudo e nos exames.

A Declaração de Bolonha foi reforçada pelas declarações do Conselho Europeu (instância decisória máxima da UE), que afirmou a necessidade de fortalecer e renovar a educação superior e a pesquisa na UE. Vejamos os comunicados:

Comunicado de Praga (2001) - Tem as seguintes questões em debate:

$\checkmark$ Aprendizagem ao longo da vida;

$\checkmark$ Envolvimento dos estudantes na gestão;

$\checkmark$ Promoção de atividades do espaço europeu da educação Superior.

Comunicado de Berlim (2003) - Reafirma objetivos de Bolonha e Praga, dando conta da decisão de colocar em funcionamento pleno o sistema europeu de créditos (ECTS - European Credit Transfer and Accumulation System). Passa a fornecer aos estudantes o Suplemento ao Diploma (documento escrito numa língua estrangeira de grande circulação onde se descreve o programa de estudos, as "competências transversais" de cada aluno.

Comunicado de Bergen (2005) - Tal como proposto pelo relatório da ENQA (Rede Europeia para a Garantia da Qualidade no Ensino Superior), onde deverão obedecer as avaliações promovidas pelas agências nacionais e internacionais, as quais virão a integrar um registro europeu de agências de garantia da qualidade, o qual exigirá, por sua vez, a meta-avaliação e a meta-acreditação das próprias agências.

Comunicado de Londres (2007) - Esforços de avanço na questão de mobilidade e comparabilidade da certificação são reportados e reiterados. Afirmando a necessidade de responder eficazmente aos desafios da globalização e construir um espaço europeu de educação superior baseado em autonomia institucional, igualdade de oportunidades e princípios democráticos que facilitarão a mobilidade, aumentará a empregabilidade e fortalecerão a atratividade e competitividade da Europa.

Comunicado de Lovaina (2009) - Reiterados os fundamentos do Processo de Bolonha como base para a pauta até 2020 . Relata as consequências que a sociedade enfrenta nesse período devido à crise econômica global, e a fim de trazer a recuperação econômica sustentável, o Ensino Superior europeu vai se esforçar para inovar com base na integração entre os ensinos. 
Considerando o investimento público no Ensino Superior de prioridade máxima.

Comunicado de Budapeste e Viena (2010) - Relembra o surgimento do Processo de Bolonha, todos os objetivos, os progressos significativos a cada comunicado e propõem medidas para facilitar a adequação e a integração dos princípios do Processo de Bolonha e as linhas de ação em todo o Ensino Superior da Europa. Através do contínuo desenvolvimento, melhoria e reforço do Espaço Europeu do Ensino Superior, afirmam que a Europa será capaz de enfrentar com êxito os desafios da próxima década.

É importante destacar que a Declaração de Bolonha (e suas atividades posteriores Processo de Bolonha) não está no âmbito estrito da UE, pois foi elaborada por um conjunto de ministros da Educação Europeia, e não tem valor legal em nível europeu. Portanto, não se caracteriza como um mandato da UE que obriga os países-membros ao seu cumprimento; é um acordo que só tem validade se os governos signatários o implementarem em seus respectivos países. Na realidade, a legislação da UE impede o estabelecimento de normas uniformes na área da educação, já que esta está sob tutela exclusiva dos Estados-membros. Em contrapartida, nem todos os ministros da Educação signatários são membros da UE.

Sem dúvida que, desde o primeiro momento a UE desempenhou um papel de liderança no Processo de Bolonha, já que um grande número de atividades e de projetos desenvolvidos no marco desse processo foi financiado e liderado por instituições da UE. Pode-se dizer que o Processo de Bolonha é um processo de todas e de cada uma das nações europeias em que a UE atua como dinamizadora

\section{PRINCIPAIS METAS DO PROCESSO DE BOLONHA}

As principais metas do Processo de Bolonha são:

1. Aumentar a competitividade: No Processo de Bolonha, competitividade é sinônimo de atratividade. A meta é melhorar a posição estratégica da educação superior europeia em nível mundial, de forma que ela seja mais atrativa para os próprios europeus e para a comunidade internacional. Pode ser alcançada por meio de uma política de melhora como também com o aumento da visibilidade do que é oferecido nas instituições de educação superior europeias. É evidente que a melhora da qualidade é a primeira condição para aumentar essa atratividade. Esta deve ser resultado de múltiplas ações: melhoras dos serviços oferecidos aos estudantes nas instituições, cursos mais estimulantes e adaptados às demandas sociais, ajuste nos planos de ensino para terem um tempo de duração real, diversidade da oferta para satisfazer as múltiplas demandas sociais e melhora de todos aqueles aspectos da educação superior. O Processo de Bolonha propõe concretamente algumas medidas para aumentar a atratividade. A primeira, que os diplomas sejam compreensíveis quer para empregadores como para estudantes de qualquer lugar do mundo. A segunda, apresentarem de forma explicita os conteúdos aprendidos durante a permanência do estudante na universidade, entendendo que estes são devem ser somente os conhecimentos adquiridos como também as competências gerais (habilidades e atitudes) necessárias ao mercado de trabalho e a vida pessoal.

2. Adaptação às demandas do mercado de trabalho: Um dos problemas da educação superior europeia é seu distanciamento do novo mercado de trabalho da sociedade do conhecimento. Neste contexto essa proposta vem a ser entendida como uma exigência de ensinar e aprender o que é relevante para o mercado de trabalho; e que as instituições de 
educação superior devem dar respostas às novas demandas sociais. É também uma proposta que, além de qualificar para as necessidades da nova sociedade, reconhece mediante um claro sistema de avaliação que os resultados pretendidos foram alcançados. Os fatores decisivos para melhorar a adaptação às demandas do mercado de trabalho são: definir claramente os objetivos de aprendizagem da cada curso, elaborar as competências (conhecimentos, habilidades e atitudes) necessárias para realizar uma determinada atividade profissional e para o desenvolvimento pessoal, e estabelecer um claro sistema de garantia de qualidade dos programas de ensino que assegurem que aquelas competências são as verdadeiramente adquiridas pelos graduados daqueles cursos. O que o Processo de Bolonha propõe para isso é um novo modelo educativo, formando as chamadas competências transversais, dentre as quais destacamos o aprendizado, conseguido não apenas por meio das fontes tradicionais, mas também da própria experiência, da de outras pessoas e das inovações cientificas e tecnológicas.

3. Mobilidade: A terceira grande meta do Processo de Bolonha é o desenvolvimento da mobilidade interna e externa para estudantes, docentes e pessoas administrativas. Essa proposta parte de dois pressupostos. O primeiro, que um amplo mercado competitivo para a educação superior servirá para melhorar a qualidade das instituições europeias; e o segundo, que é necessário desenvolver a cidadania europeia por meio do profundo conhecimento de outros países e culturas. Para sua viabilidade, torna-se necessário que as estruturas educativas nos diferentes países sejam passiveis de comparação a fim de tornar possível o reconhecimento de cursos concluídos em outro país. E respeitar a diversidade significa que a comparação deva ser baseada em um modelo flexível que reconheça, quer os conhecimentos básicos transmitidos por outros sistemas educativos, quer a qualidade de outras instituições. Para a implementação dessa proposta, foi criado em 1988 o programa ERASMUS, que mobilizou até hoje mais de um milhão de estudantes europeus. Por meio desse programa, a UE concede apoio econômico aos estudantes que desejam estudar um semestre letivo em outro país da UE. Esse apoio não cobre todos os gastos, porém o que torna o programa atrativo é o fato de as instituições que recebem os estudantes terem a obrigação de tratá-los como seus próprios estudantes e facilitar-lhes a integração na instituição. Em contrapartida, a instituição de origem tem a obrigação de reconhecer os créditos de disciplinas/cursos concluídos naquele semestre na universidade estrangeira. O sucesso do programa e a necessidade de ampliar essa mobilidade criaram as condições para elaboração de um novo programa de intercambio, não restrito aos cidadãos da UE. Trata-se do programa ERASMUS Mundus (2004), cujo objetivo é realizar intercambio de estudantes de todo o mundo, mediante apoio financeiro para fazer cursos de segundo ciclo nas universidades europeias ou em universidades associadas de outros países.

\section{ALGUNS INSTRUMENTOS DO PROCESSO DE BOLONHA}

Alguns dos mais importantes instrumentos no Processo de Bolonha e que despertaram grande interesse dentro e fora da Europa são: O suplemento do diploma, os créditos europeus (ECTS) e a estrutura dos graus em ciclos.

O Suplemento ao Diploma é um documento complementar do Diploma, elaborado pela Comissão Europeia, pelo Conselho da Europa e pela UNESCO/CEPES, que tem por objetivo fornecer dados independentes e suficientes para melhorar a transparência internacional e o reconhecimento acadêmico e profissional equitativo das qualificações (diplomas, graus, certificados, etc.); 
Segundo a portaria n. $30 / 2008$ de 10 de Janeiro em seu artigo 1으, o suplemento ao diploma é um documento complementar do diploma, é um documento bilíngue, escrito em português e inglês. Sua emissão é gratuita e obrigatória, sempre que emitido diploma e só neste caso, conforme discorrido no artigo 2‥

Complementam os dois documentos que habitualmente certificam uma formação: o diploma e o certificado de habilitações.

A sua função principal é a de explicar a formação que foi adquirida em termo de:

$\checkmark$ Nível de qualificação (grau acadêmico e/ou profissional);

$\checkmark$ Conteúdo (módulos, unidades curriculares, estágios, etc.) e resultados obtidos (classificações, créditos, sistema de classificações, etc.);

$\checkmark$ Função da qualificação (acesso a outros estudos, acesso a profissão, etc.).

Outro instrumento generalizado no Processo de Bolonha é o dos créditos europeus, que se chama European Credit Trandfer System, reconhecido pela sigla ECTS, ou seja, Sistema Europeu de Transferência de Créditos, que através de procedimentos comuns garante o reconhecimento acadêmico da formação e graus obtidos pelos estudantes no espaço europeu.

O ECTS é um sistema de medida do trabalho regulamentada pelo Decreto Lei $n$ o 49/2005 de 30 de agosto define em seu Artigo 13 que "os créditos são a unidade de medida do trabalho do estudante", necessário para que um estudante complete com êxito uma determinada unidade curricular.

A definição dos créditos dos cursos é dada através do número de horas de trabalho do estudante a considerar inclui todas as formas de trabalho previstas, designadamente as horas de contato e as horas dedicadas a estágios, projetos, trabalhos no terreno, estudo e avaliação conforme, Decreto Lei no 49/2005 de 30 de agosto art. 13ㅇ.

O sistema estabelece que um crédito seja equivalente a 25-30 horas de trabalho do estudante (permite-se certa flexibilidade na definição exata dos créditos), e que um ano acadêmico deve representar um total de 60 créditos. Assim, se o curso estiver adequadamente concebido, um estudante "normal" não deverá se atrasar para concluí-lo. Os créditos podem ainda ser acumuláveis e transferíveis para outras formações, outras escolas, outros países e podem ainda ser utilizados para o reconhecimento acadêmico de determinado tipo de competências (de natureza profissional, por exemplo).

O sistema de créditos assegura mobilidade aos estudantes entre os estabelecimentos de Ensino Superior nacionais, do mesmo ou de diferentes subsistemas, bem como entre estabelecimentos de Ensino Superior estrangeiro e nacional, com base no princípio do reconhecimento mútuo do valor da formação e das competências adquiridas.

Entende-se aqui "a globalização do trabalho de formação do aluno, incluindo as horas de contato, de projeto, de trabalho de campo, o estudo individual e as atividades relacionadas com avaliação, abrindo-se também a atividades complementares com comprovado valor formativo artístico, sociocultural ou desportivo" (Decreto Lei no 42/2005).

Talvez o mais conhecido instrumento elaborado no Processo de Bolonha para facilitar a comparabilidade dos graus nas estruturas educativas europeias seja o da estrutura de três ciclos, adotado pela Lei de Bases do Sistema Educativo e alterada pelo Decreto Lei no 49/2005 de 30 de 
agosto.

Os ciclos de estudo são conjuntos organizados de unidades curriculares em que o estudante deve obter aprovação, para obter um grau acadêmico. Tradicionalmente, a maioria dos cursos europeus é de longa duração (em torno de cinco anos), e, na prática, é maior o tempo que os estudantes levam para concluir satisfatoriamente o curso. A proposta do novo sistema é estabelecer três ciclos: o primeiro (grau de licença) com carga de 180 a 240 créditos (entre três e quatro anos de duração), o segundo ciclo (grau de mestre) entre 60 e 120 créditos (um ou dois anos de duração) e o terceiro (grau de doutor) sem duração definida.

Cada instituição, cada país ou cada curso poderá definir essa estrutura de forma distinta, porém dentro dos limites propostos. Uma condição requerida é que o diploma do primeiro ciclo deva ter relevância para o mercado de trabalho, ou seja; não deva ser a simples divisão de um curso de longa duração em dois períodos mais curtos, e sim realizar uma verdadeira transformação curricular que permita a entrada no mercado de trabalho daqueles que concluíram o primeiro ciclo. Alguns cursos como medicina, arquitetura ou veterinária são excluídos dessa estrutura, já que serão sempre organizados como cursos de longa duração.

\section{O PROCESSO DE TRANSIÇÃO} curricular:

O Decreto Lei n. 107/2008, Capítulo IV, artigo 66으 regulamenta sobre a transição

As regras de transição entre a anterior organização de estudos e a nova organização decorrente do processo de adequação são fixadas pelos órgãos legal e estatutariamente competentes, após audição de docentes e alunos através dos órgãos científico e pedagógico do estabelecimento de ensino e ou da unidade orgânica, conforme for o caso.

As regras de transição devem assegurar: o respeito pelas legítimas expectativas dos alunos; os necessários regimes de acreditação na nova organização de estudos da formação obtida na anterior organização; e que da sua aplicação não resulte um aumento da carga letiva prevista na anterior organização.

A coexistência entre a nova organização de estudos e a anterior, se prevista nas regras de transição, não deve exceder um ano letivo, podendo, excepcional e justificadamente, prolongarse por mais um (Decreto Lei n.o 107/2008).

O processo de transição da organização tradicional das formações para a organização das mesmas de acordo com a Declaração de Bolonha não é, no essencial, diferente da transição que se faz quando se alteram os planos curriculares de um curso.

Existe um plano de estudo de um curso, com um conjunto de unidades curriculares, as quais vão ter, ou não, equivalência a outro conjunto de unidades curriculares num plano de estudo novo.

A diferença mais importante é que nas anteriores transições curriculares, quando uma unidade curricular não tinha equivalência podia considerar-se mais ou menos perdida - ficava o conhecimento adquirido, mas não certificado. Agora, mesmo que uma determinada unidade curricular deixe de constar de um plano de estudo ela é sempre certificada através do Suplemento ao Diploma, e os créditos que lhe forem atribuídos constituem um valor por si mesmo. 
O IPL (Instituto Politécnico de Leiria), citando como exemplo, foi uma das instituições de Ensino Superior que se adequou ao Processo de Bolonha, aprovando o regulamento:

Regulamento №. 87/2006. - Tendo sido aprovado, por unanimidade, por deliberação do conselho geral do Instituto Politécnico de Leiria de 18 de Maio de 2006, em anexo se publica o regulamento do regime de transição dos cursos de bacharelado e licenciatura ministrados no Instituto Politécnico de Leiria para a nova organização decorrente da adequação ao Processo de Bolonha.

Fundamentalmente o Regulamento aprovado, o IPL tratou de forma diferenciada os estudantes, consoante $o$ ano do curso em que se encontrem, de modo a garantir que nenhum aluno conclua o seu curso sem que tenha tido oportunidade de adquirir todas as competências indispensáveis para o exercício das profissões para que o curso habilite. Assim, os estudantes que não tinham concluído os seus bacharelados e que se encontravam matriculados no 10 e 20 anos dos cursos na anterior organização curricular transitaram diretamente para a nova organização. Os estudantes matriculados no 30 ano transitaram para o novo plano de estudo podendo as unidades curriculares que the foram exigidas para concluir o seu curso, além das previstas, exceder as 15 créditos.

\section{SISTEMA DE AVALIAÇÃO DO ENSINO SUPERIOR AMERICANO}

Em um país onde a cultura do vestibular não existe, os currículos dos alunos da HighSchool (ou ensino médio) tendem a ser cada vez mais competitivos. Os estudantes americanos sabem que cada ano da High-School é um passo muito importante na disputa por uma vaga em uma boa IES do país. Nesse contexto, os jovens estrangeiros que pretendem fazer uma graduação nos Estados Unidos devem estar cientes das dificuldades que o sistema impõe, da competitividade existente entre os candidatos e, principalmente, das inúmeras diferenças em relação ao modelo brasileiro de Ensino Superior.

Com Exceção dos cursos de Medicina, Veterinária, Direito e Odontologia (que têm uma formação diferenciada) todas as outras áreas de habilitação do Ensino Superior americano contam com três diferentes etapas: Graduação, Mestrado e Doutorado.

$\mathrm{O}$ termo undergraduated refere-se à educação que os americanos recebem depois que terminam o segundo grau. De modo geral, os cursos estão distribuídos em três grandes áreas acadêmicas: humanidades, ciências sociais e ciência da saúde, e as disciplinas podem ser obrigatórias ou opcionais. Elas estão divididas em dois grandes grupos, dependendo de sua duração: Curso superior de curta duração (Associated Degrees) e Licenciatura (Bachelors Degrees).

Cursos superiores de curta duração (Associated Degrees): O curso superior de curta duração, ou grau de associado, são programas acadêmicos que foram elaborados para serem concluídos em dois anos. Os créditos obtidos nos programas desses cursos em geral são reconhecidos pelas instituições como parte das licenciaturas de quatro anos. As pessoas que entram nos cursos superiores de curta duração com frequência pretendem mudar para um programa de licenciatura e algumas vezes podem fazê-lo antes de terminar os dois anos. Os cursos superiores de curta duração são constituídos por uma base teórica geral, complementada por disciplinas específicas em função da especialidade que se deseja cursar. Nesses dois anos, é possível adquirir um título em áreas tão variadas quanto à enfermagem, profissões relacionadas 
com a saúde, especializações de negócios ou temas tecnológicos.

Licenciaturas (Bachelors Degrees): Licenciaturas ou bacharelados são cursos universitários com duração total de quatro anos, nos quais o aluno deve cumprir uma série de créditos em função da especialidade escolhida. Em cada ano de estudo o aluno recebe uma denominação diferente. As especialidades de humanidades, ciências sociais, filosofia, estudos religiosos, estudos interdisciplinares ou da área cultural em geral recebem uma licenciatura em Artes (B.A. ou A.B.). Os programas de matemática, física, engenharia e outros campos profissionais podem receber um B.A., uma licenciatura em Ciências (B.S. ou S.B.) ou um título com o nome específico da matéria estudada.

Os anos de graduação são divididos em quatro etapas:

$\checkmark$ Freshman e Sophomore: Equivalem, respectivamente, ao primeiro e segundo anos de graduação de uma IES americana. Nestas etapas, o curso aplica disciplinas de conhecimento geral. Essa iniciativa permite que o aluno tenha mais tempo para se decidir sobre a carreira a seguir, além de não precisar ingressar em uma instituição e, logo no primeiro ano, estudar matérias específicas de uma determinada habilitação.

$\checkmark$ Junior: Corresponde ao terceiro ano do curso de graduação, em que o aluno poderá escolher qual a habilitação deseja se especializar. Essa opção chama-se Major (habilitação em que o estudante deseja concluir seu bacharelado). Após a escolha de seu Major o aluno poderá optar, caso tenha interesse, por cursar o Minor, ou seja, matérias eletivas secundárias relacionadas à habilitação em que deseja se especializar.

$\checkmark$ Senior: Corresponde ao quarto e, com exceção dos cursos de Medicina, Veterinária, Direito e Odontologia, o último ano de graduação de uma IES americana.

Os cursos de Medicina, Odontologia, Veterinária e Direito, têm um processo um pouco diferente dos demais. No terceiro ano, ou Junior, o estudante não escolherá a habilitação específica como medicina e direito, por exemplo. Nesses casos, ele irá optar por uma habilitação em: Pre-Med, Pre-Dental, Pre-Vet ou Pre-Law, que correspondem a um preparo inicial do curso em que desejam se formar. Após a conclusão do Senior, o aluno é submetido a um exame onde serão testados seus conhecimentos. Caso seja aprovado, o mesmo é encaminhado para uma Professional School onde poderá concluir o restante de seu curso e, por fim, exercer sua profissão. O tempo de conclusão do curso pode variar entre quatro e oito anos.

Nos Estados Unidos são considerados cursos de pós-graduação apenas o mestrado e doutorado. Outros cursos oferecidos após a graduação, ou mesmo durante esta última, são considerados apenas de extensão ou especialização. Os cursos de especializações são chamados de Certificate Programs, Short Courses ou Continuing Education.

Para que o candidato a mestre nos Estados Unidos conclua o curso é necessário à elaboração de defesa de um trabalho de pesquisa conhecido com dissertação de mestrado. Os mestrados acadêmicos podem ser enquadrados em três diferentes categorias:

$\checkmark$ MA ou Master of Arts: Engloba diferentes áreas do conhecimento como: Economia, Folclore, Antropologia e Inglês.

$\checkmark$ MS ou Master of Science: Engloba áreas do conhecimento como: Arquitetura, Ciência da Computação e Engenharia Química.

$\checkmark$ MFA ou Master of Fine Arts: Engloba áreas do conhecimento como: Fotografia e 
Teatro.

Todos os outros certificados são enquadrados na categoria profissional.

Muitas escolas de graduação consideram o mestrado como o pontapé inicial para a obtenção de um doutorado. Porém existem instituições em que o estudante pode se preparar diretamente para o doutorado, sem a necessidade de obter um título de mestre. O grau de doutorado certifica que um estudante adquiriu o conhecimento necessário para trabalhar como professor universitário no campo em que se especializou. Esses programas podem ser divididos em duas partes. Na primeira parte, com duração de três a cinco anos, o estudante deve assistir aulas junto com outros alunos, prestando um exame no final para demonstrar os conhecimentos que adquiriu durante os anos de estudo. Superado esse exame, o estudante entra na segunda fase, de dois ou três anos de duração, quando concentra seus esforços no desenvolvimento de uma pesquisa sobre algum aspecto relevante de seu tema de estudo, escrevendo uma tese sobre o mesmo e defendendo-a perante uma banca composta por especialistas no tema.

\section{AGÊNCIAS ACREDITADORAS E PROCESSO DE ACREDITAÇÃO DAS INSTITUIÇÕES DE ENSINO}

O sistema educacional americano é descentralizado, cada um dos 50 Estados Americanos tem sua autonomia, independentemente do Governo Federal, são respeitadas as legislações diferentes de cada Estado.

Nos 50 Estados americanos, soma-se mais de 3.200 universidades e faculdades, essas com Ensino Superior presencial e a distância, havendo mais de 27.000 cursos superiores desenvolvidos.

Não há Ministério da Educação nos Estados Unidos. O Departamento de Educação (Governo Federal) tem o controle da educação como um todo (verbas, aspectos constitucionais, bolsas de estudos...). As Secretárias de Estado têm plena autonomia legal para autorizar o funcionamento das instituições de Ensino Superior em seus próprios Estados. As faculdades e Universidades gozam, nos Estados Unidos, verdadeiramente, de plena autonomia, na acepção da palavra.

O diploma americano não tem validade em todo país. O diploma americano tem somente validade no Estado em que foi emitido e nos Estados conveniados com o Estado emitente do diploma. Para a legalização do diploma em outros Estados americanos é necessário convalidá-lo no outro Estado, em que desejar o diplomado trabalhar.

As Faculdades e Universidades americanas não têm obrigatoriedade, regida em lei, de estarem registradas no DETC (Distance Education and Training Council), com vistas ao seu funcionamento legal. O DETC é uma instituição privada, conceituada, mas não governamental. A maioria das instituições americanas não é associada ao DETC e não perdeu, por esta razão, sua legalidade e legitimidade nos Estados Unidos, nem em qualquer outro país no mundo, para oferecer Ensino Superior e a distância, além de emitir os seus diplomas de conclusão nos Estados Unidos. Muitas outras Faculdades e Universidades têm o registro quase automático no DETC ou Associações Regionais, porque já o tinham como instituição presencial e não necessitam, novamente, associar-se, quando decidiram ministrar a educação à distância, em suas instalações, tomadas por decisões de sua autonomia universitária.

Muitos Estados Americanos exigem que o registro de suas Faculdades e Universidades 
presenciais em Associações Regionais de Acreditação, privadas, quando credenciadas pelo Departamento de Educação/EUA. Nos casos, cabe a decisão à Reitoria da Universidade, considerados, portanto, opcionais às instituições que desenvolvem, isoladamente, a Educação a Distância.

O sistema de avaliação do Ensino Superior americano é feito através da acreditação das universidades e faculdades através de associações de acreditação previamente reconhecidas. Existem duas organizações que reconhecem essas agências de acreditação nos Estados Unidos, o departamento de educação nos Estados Unidos, U.S Department of Education (USDE), ou Council for Higher Education Acreditation (CHEA), conselho de reconhecimento do Ensino Superior. Muitos estados americanos exigem o registro de suas faculdades e universidades presenciais em associações regionais de acreditação.

O reconhecimento das instituições de Ensino Superior nos Estados Unidos é opcional por parte das instituições. È um processo não governamental, um processo independente.

Existem dois tipos de reconhecimento:

$\checkmark$ Reconhecimento Institucional: A instituição é reconhecida como um todo.

a. Reconhecimento Regional: São seis associações regionais de reconhecimento com o objetivo de avaliar a instituição como um todo. O reconhecimento é concedido para a instituição em sua totalidade. Praticamente a maioria das instituições regionalmente reconhecidas automaticamente reconhece os diplomas e os cursos feitos em outra instituição também reconhecida.

b. Reconhecimento Nacional: Existem grupos que avaliam e reconhecem instituições com especializações ou interesses diversos nos Estados Unidos. Algumas vezes essas instituições também são reconhecidas regionalmente. A maioria das instituições reconhecidas não aceita diplomas ou cursos feitos em instituições sem reconhecimento, a não ser que as mesmas sejam também regionalmente reconhecidas.

$\checkmark$ Reconhecimento por organizações profissionais: reconhecimento de programas específicos de estudos dentro de uma instituição, ou a instituição como um todo, se oferecer apenas um programa de estudo. Uma instituição que é "regionalmente reconhecida" pode oferecer vários "programas reconhecidos". Em algumas áreas de estudo, os alunos formados devem ter seu diploma reconhecido, para que sejam autorizados a exercer sua profissão.

O objetivo do credenciamento, é garantir que o ensino ministrado por instituições de Ensino Superior, atenda aos níveis aceitáveis de qualidade.

As agências de acreditação, que são associações privadas de ensino de âmbito regional ou nacional, desenvolvem critérios de avaliação e realizam avaliações de pares para avaliar se esses critérios são cumpridos ou não nas instituições. As instituições e/ou programas em que ocorre pedido de avaliação de uma agência, e que a avaliação satisfaz os critérios da agência são, então, "credenciado" por essa agência.

O Departamento de Educação dos Estados Unidos não credencia instituições de ensino e/ou programas. No entanto, o secretário de Educação é obrigado por lei a publicar uma lista de agências de acreditação reconhecida a nível nacional que a Secretária determina a autoridades 
confiáveis sobre a qualidade da educação ou da formação ministrada pelas instituições de Ensino Superior e a programas de educação superior que são credenciadas. As agências devem satisfazer os procedimentos, determinados pelo secretário e os critérios para o reconhecimento, conforme é publicado em documento federal.

Nos EUA, os acreditadores podem ser privados ou organizações não-governamentais criada com a finalidade específica de analisar as instituições de Ensino Superior e programas com relação à qualidade.

Além da apresentação de um pedido para o Departamento de Educação dos EUA, o processo de reconhecimento envolve também a fiscalização do comitê consultivo Nacional sobre Qualidade e Integridade Institucional, fazendo recomendações ao secretário em matéria de reconhecimento. Após o secretário considerar a recomendação da Comissão, faz a determinação final sobre o reconhecimento, com isso a agência é então reconhecida para avaliar as instituições de Ensino Superior, podendo acreditá-las ou não, dependendo do cumprimento das normas.

Conforme o CHEA, as normas de reconhecimento das agências de acreditação de instituições de Ensino Superior americana, está relacionado ao avanço da qualidade acadêmica (os acreditadores têm uma descrição clara da qualidade acadêmica, em que as instituições ou programas que eles acreditam devem ter processos, para determinar se os padrões de qualidade estão sendo cumpridos) e a demonstração de qualidade (acreditadores têm normas que exigem das instituições e programas que forneçam informações verdadeiras e confiáveis sobre a qualidade acadêmica e o desempenho acadêmico dos alunos para promover a contínua confiança do público e do investimento).

Segundo o Conselho de Acreditação do Ensino Superior, as instituições de acreditação devem:

$\checkmark$ Incentivar, autoanalisar e planejar mudanças e melhorias necessárias, através de autoexame nas instituições e programas.

$\checkmark$ Empregar procedimentos justos e adequados na tomada de decisões, onde os acreditadores mantêm políticas justas nos procedimentos organizacionais, incluindo controles eficazes e saldos.

$\checkmark$ Demonstrar a revisão em curso das práticas de acreditação. É realizados autoexame das suas atividades acreditadas.

$\checkmark$ Possuir recursos suficientes, ou seja, as acreditadoras devem ter e manter recursos previsíveis e estáveis.

O principal objetivo do reconhecimento feito pelo CHEA é assegurar e reforçar a qualidade acadêmica e a melhoria contínua da qualidade dos cursos, programas e graus.

Nessas políticas e procedimentos, eles exigem que acreditadores busquem aprimorar a qualidade acadêmica, demonstrando responsabilidade, incentivando a mudança intencional e melhorias necessárias, utilizando procedimentos justos e adequados na tomada de decisões, e reavaliando constantemente as práticas de acreditação e buscando sustentar a estabilidade fiscal.

Os acreditadores do CHEA são geralmente revistos em um ciclo de 10 anos com dois relatórios intercalares. A revisão é realizada pela comissão do CHEA, um grupo de representantes institucionais, credenciadores e membros externos, que verificam acreditadores para eleger ao CHEA e o reconhecimento de acreditadores revisando com base no acreditador através de uma 
auto avaliação. A revisão também pode incluir uma visita ao local.

A acreditação é o principal meio pelo qual a qualidade das instituições de Ensino Superior e dos programas está assegurada nos Estados Unidos. A acreditação é uma forma de auto regulação em que faculdades, universidades e programas se uniram para desenvolver normas, políticas e procedimentos para a auto avaliação e julgamento por pares.

Existem quatro tipos de organizações de acreditação:

$\checkmark$ Regional - Credenciam as instituições públicas e privadas, sem fins lucrativos e, principalmente grau de concessão, de dois e quatro anos.

$\checkmark$ Nacional fé-relacionada - Credenciam filiação religiosa e baseado na doutrina das instituições, principalmente sem fins lucrativos e de concessão de grau.

$\checkmark$ Nacional relacionada à carreira - Credenciar, principalmente com fins lucrativos, a carreira baseada instituições, com um único propósito, tanto de graduação e pós-graduação.

$\checkmark$ Programáticas. Credenciar os programas específicos, profissões liberais e autônomos escolas, por exemplo, direito, medicina, engenharia e profissões da saúde.

As organizações acreditadoras devem periodicamente disponibilizar informações sobre instituições e programas que estão acreditados; tempo de credenciamento de uma instituição ou um programa; informações se uma instituição credenciada ou programa está sob sanções e uma descrição dessas sanções; manter um resumo das ações recentes tomadas por organizações acreditadas, geralmente fornecidas após as reuniões de órgãos de decisão e, para algumas organizações, oferecer dados agregados ou perfis das instituições ou programas que sejam credenciados.

Uma instituição ou um programa de busca de acreditação deve passar por uma série de medidas estipuladas por uma organização de acreditação. Essas etapas envolvem uma combinação de várias tarefas: elaboração de provas de realização, pela instituição ou programa, a análise dessa prova e uma visita ao local por professores e colegas administrativos e de ação pela organização de acreditação para determinar o estatuto de acreditação.

Acreditação não prevê a aceitação automática de uma instituição que se credenciou em outra instituição, nem dá garantias de aceitação de diplomados por parte dos empregadores. Aceitação de crédito ou licenciados é sempre uma prerrogativa da instituição de acolhimento ou empregador. Por estas razões, além de verificar o status de acreditado de uma escola ou curso, o aluno deve tomar medidas adicionais para determinar, antes da matrícula, se os seus objetivos educacionais serão alcançados através da participação em uma instituição particular.

Alguns motivos levam as instituições a buscarem a acreditação, entre eles:

$\checkmark$ Acesso a recursos federais e estaduais - A acreditação é necessária para o acesso a verbas federais, como a ajuda de estudantes e outros programas federais. Os fundos de ajuda federal para o estudante estão disponíveis para os alunos somente se a instituição ou programa que estão frequentando é credenciado por um organismo de acreditação reconhecido.

$\checkmark$ Gerar confiança do setor privado - Estatuto de acreditação de uma instituição ou programa é importante para os empregadores quando se avalia as credenciais dos candidatos a emprego e quando decidir se a prestar apoio de matrícula para os 
funcionários atuais em busca de formação adicional.

$\checkmark$ Facilitar a transferência - O credenciamento é importante aos estudantes, para que o processo de transferência de cursos e programas entre as faculdades e universidades, se necessário seja feito de forma mais fácil.

\section{COMPARATIVO ENTRE A METODOLOGIA EUROPÉIA X METODOLOGIA AMERICANA}

O Ensino Superior nos Estados Unidos é semelhante, em partes, ao Processo de Bolonha. Em ambos os primeiros anos de graduação são de formação científica e cultural, e só depois os egressos tem acesso a cursos de mestrado ou doutorado, definidores de profissões. O que torna um ponto positivo, pois não há excessiva precocidade na escolha de carreira profissional. São considerados cursos de pós-graduação apenas o mestrado e doutorado.

O Processo de Bolonha é composto por 47 países, onde os mesmos comprometeram-se em reorganizar o sistema de Ensino Superior dos seus países de acordo com os princípios da Declaração de Bolonha, ou seja, são países distintos que seguem uma arquitetura unificada de educação superior, diferente dos Estados Unidos, onde o sistema é descentralizado, cada um dos 50 Estados Americanos tem sua autonomia, independentemente do Governo Federal, respeitando as legislações diferentes de cada Estado. Não há Ministério da Educação nos Estados Unidos. O Departamento de Educação (Governo Federal) tem o controle da educação como um todo (verbas, aspectos constitucionais, bolsas de estudos e etc). As Secretárias de Estado têm plena autonomia legal para autorizar o funcionamento das instituições de Ensino Superior em seus próprios Estados. As faculdades e Universidades gozam, nos Estados Unidos, verdadeiramente, de plena autonomia, na acepção da palavra.

O diploma americano não tem validade em todo país. O diploma americano tem somente validade no Estado em que foi emitido e nos Estados conveniados com o Estado emitente do diploma. Para a legalização do diploma em outros Estados americanos é necessário convalidá-lo no outro Estado, em que desejar o diplomado trabalhar. Ao contrário, acontece com o diploma estabelecido pela Declaração de Bolonha, são automaticamente reconhecidos em todos os estados aderentes, facilitando dessa forma, o reconhecimento das qualificações e a mobilidade das pessoas.

\section{CONSIDERAÇÕES FINAIS}

As universidades americanas que por meio século atraíram os melhores e mais brilhantes estudantes do mundo com pouco esforço, estão repentinamente enfrentando uma forte concorrência, à medida que o Ensino Superior passa por rápida globalização. A União Europeia, atuando metodicamente para competir com as universidades americanas, está modernizando o seu sistema de Ensino Superior e oferecendo cursos ao estilo americano ministrados em inglês. Grã-Bretanha, Austrália e Nova Zelândia estão recrutando agressivamente estudantes estrangeiros, assim como centros asiáticos como Taiwan e Hong Kong. E a China, que declarou a transformação de 100 universidades em instituições de pesquisa de nível mundial como uma prioridade nacional, está persuadindo os maiores estudiosos chineses a voltarem das universidades americanas para casa. 
Segundo Payne, diretor executivo do Serviço de Teste Educacional, "o que estamos começando a ver em termos dos estudantes internacionais agora dispondo de opções além dos Estados Unidos para ensino de alta qualidade é apenas a ponta do iceberg", disse, que realiza vários testes para que estudantes estrangeiros tenham acesso às universidades americanas.

Ainda conforme Payne, outros países estão começando a expandir sua capacidade de oferta de Ensino Superior. "No futuro, os estudantes estrangeiros terão muito mais oportunidades." Os estudantes estrangeiros contribuem anualmente com US\$ 13 bilhões para a economia americana. Em julho de 2004, Payne informou à Academia Nacional de Ciência sobre a queda acentuada no número de estudantes da Índia e da China que realizaram o mais recente Graduate Record Exam (exame de histórico de graduação), obrigatório para aqueles que se candidatam à maioria dos cursos de pós-graduação; ele caiu pela metade. Enquanto isso, as matrículas em universidades aumentam na Inglaterra, Alemanha e outros países. Parte do declínio americano, concordam os especialistas, se deve aos atrasos pós-11 de setembro no processamento dos vistos de estudante, o que tem desencorajado milhares de estudantes, não apenas do Oriente Médio, mas também de dezenas de outros países, a se matricularem nos Estados Unidos. Os educadores americanos e até mesmo alguns estrangeiros dizem que as dificuldades com vistos estão ajudando as escolas estrangeiras a aumentarem sua participação no mercado.

Os educadores americanos estão preocupados desde o outono de 2002, quando um grande número de estudantes estrangeiros enfrentou atrasos no processamento de vistos. Mas poucos notaram o rápido crescimento do Ensino Superior como uma indústria global até recentemente. Os países que exportam mais estudantes são a China, Coréia do Sul e Índia, mas a migração global anual para universidades estrangeiras envolve 2 milhões de estudantes de muitos países viajando em muitas direções. Tal número está explodindo - segundo algumas estimativas ele quadruplicará até 2025 - à medida que o crescimento econômico produz milhões de novos estudantes de classe média por toda a Ásia.

A Austrália e Nova Zelândia, buscando uma abordagem de "geração de receita", tratam o Ensino Superior como uma indústria, cobrando plenamente os custos dos estudantes estrangeiros. Elas concorrem eficazmente no mercado mundial por oferecerem ensino de qualidade e os custos para alguns cursos nestes países são mais baixos do que nos Estados Unidos. Países emergentes como Índia, China e Cingapura, seguindo uma abordagem "formação de capacidade", veem o estudo no exterior por milhares dos estudantes de seus países como uma forma de treinar futuros professores e pesquisadores para suas próprias universidades, que estão expandindo rapidamente.

Para concluir o estudo é relevante apontar que o sistema de avaliação brasileiro, se difere do americano, comparado nesta pesquisa, porém o sistema brasileiro está se aperfeiçoando cada vez mais, e buscando melhorar as percepções dos cursos, assim como das instituições de ensino, visando melhorar a qualidade do serviço prestado, e assim contar com profissionais cada vez mais preparados para mercado de trabalho.

\section{REFERÊNCIAS BIBLIOGRÁFICAS}

1. _- Universidade Nova: nem Harvard, nem Bolonha. Disponível em: http://www.twiki.ufba.br/twiki/bin/view/UniversidadeNova/Artigo_n1. 
2. Comunicado de Bergen. Disponível em: http://www.bologna-bergen2005.no/Docs/00Main_doc/050520_Bergen_Communique.pdf.

3. Comunicado de Berlim. Disponível em: http://www.ond.vlaanderen.be/hogeronderwijs/bologna/links/language/2003_Berlin_comm unique_Portuguese.pdf.

4. Comunicado de Budapeste e Viena. Disponível em: http://www.ond.vlaanderen.be/hogeronderwijs/bologna/2010_conference/documents/Buda pest-Vienna_Declaration.pdf

5.

6. Comunicado de Londres. Disponível em: http://www.crue.org/export/sites/Crue/procbolonia/documentos/antecedentes/Comunicado _de_Londres_2007.pdf

7. Comunicado de Lovaina.

Disponível em: http://www.ond.vlaanderen.be/hogeronderwijs/bologna/conference/documents/Leuven_Lo uvain-la-Neuve_Communiqu\%C3\%A9_April_2009.pdf

8. Comunicado de Praga. Disponível em: http://www.ond.vlaanderen.be/hogeronderwijs/bologna/links/language/2001_Prague_Com munique_Portuguese.pdf

9. Declaração de Bolonha. Disponível em: http://www.ond.vlaanderen.be/hogeronderwijs/bologna/links/language/1999_Bologna_Decl aration_Portuguese.pdf.

10. HOTALE, Virginia Alonso. Tendência para reformas da educação superior na Europa no contexto do Processo de Bolonha. Sociologias (17): 22-49. 2007 Jun.

11. PORTUGAL. Ministério da Ciência Tecnologia e Ensino Superior. Direcção Geral do Ensino Superior. $O$ Processo de Bolonha. Lisboa, 2008. Disponível em: http://www.dges.mctes.pt/DGES/pt/Estudantes/Processo+de+Bolonha/Processo+de+Bolonh a/ Acesso em: 17 out. 2011.

12. Ministério da Ciência Tecnologia e Ensino Superior. Decreto Lei n.o 49/2005. Disponível em: http://www.dges.mctes.pt/DGES/pt/decreto+lei+49/2005/. Acesso em: 17 out. 2011.

13. Ministério da Ciência Tecnologia e Ensino Superior. Decreto Lei n.o 107/2008. Disponível em: http://www.dges.mctes.pt/DGES/pt/decreto+lei+107/2008/ . Acesso em: 17 out. 2011.

14. . Ministério da Ciência Tecnologia e Ensino Superior. Portaria 30/2008. Disponível em: http://www.dges.mctes.pt/DGES/pt/portaria+30/2008/ . Acesso em: 17 out. 2011.

15. ROBERTSOM, Susan L. O processo de Bolonha da Europa torna-se global: modelo, mercado, mobilidade, força intelectual ou estratégia para constrção do Estado? Rev. Bras. Educ. 14(42): 407-422, ILUS. 2009 Dec.

16. WIELEWICKI, Hamilton de Godoy; OLIVEIRA, Marlize Rubin. Internacionalização da educação superior: processo de Bolonha. Ensaio: aval.pol.públ.Educ. 18(67): 215-234, TAB. 